\title{
NOVAS ESTRATÉGIAS DE ENSINO DA LÍNGUA INGLESA PARA UM APRENDIZADO SIGNIFICATIVO DE CRIANÇAS E ADOLESCENTES
}

\author{
GUILHERME GARCIA DE ALMEIDA \\ Graduado em Letras/Pós-graduado em Psicopedagogia \\ LUCIAN DA SILVA BARROS \\ Psicólogo/Pós-graduado em Ética, valores e cidadania na escola
}

\begin{abstract}
RESUMO
Devido ao foco excessivo em resultados como boas notas e domínio de uma língua, muitas instituições de ensino tendem a negligenciar todo o processo de ensino-aprendizagem, gerando assim uma padronização de ensino. Essa perspectiva afeta diretamente o trabalho dos professores dentro de sala de aula, pois com a propagação de tal visão, seu objetivo torna-se apenas expor conteúdos, sem haver preocupação com a individualidade e as necessidades de cada aluno. A partir desse contexto, o objetivo deste artigo é promover uma reflexão sobre como professores podem construir um processo mais significativo de ensino-aprendizagem da língua inglesa. Para atingir tal meta, três metodologias, baseadas nas ideias de Florinda Marques (2012), foram apresentadas e uma sequência didática foi criada para ilustrar a teoria. Concluiu-se que os professores só serão capazes de ensinar de maneira efetiva caso planejem todas as etapas de suas aulas com bastante cuidado e criatividade, sempre oferecendo aos alunos oportunidades de adotar um papel mais ativo na construção do próprio conhecimento. Além disso, todas as suas atividades e métodos avaliativos devem ser aplicados baseando-se nos conceitos de afetividade, competência comunicativa e habilidades linguísticas. Palavras-chave: Processo ensino-aprendizagem; ensino de inglês; competência comunicativa.
\end{abstract}




\begin{abstract}
Due to the excessive focus on results, such as good grades and language acquisition, many schools tend to neglect the entire teaching-learning process, causing a standardization of education as a result. This perspective affects the teachers' work inside the classroom directly, since the propagation of this point of view limits their goals to simple knowledge exposition, without any concern about each student's individuality and needs. Taking this context into consideration, the objective of this paper is to promote a reflection on how teachers can build a more meaningful learning-teaching process of English. In order to achieve this goal, three different methodologies based on Florinda Marques' (2012) ideas were presented and one lesson plan was built to illustrate the theory. In conclusion, teachers will only be able to teach effectively if they manage to plan every step of their classes carefully and creatively, always providing students with the opportunity of taking a more active role in building their own knowledge. In addition to that, all activities and evaluation methods must be applied based on the concepts of affectivity, communicative competence and language skills.
\end{abstract}

Keywords: Teaching-learning process; English teaching; communicative competence.

\title{
INTRODUÇÃO
}

A língua nasceu como um instrumento comunicativo utilizado para produzir sentimentos, ideias e permitir diferentes tipos de interações. Como consequência de tais produtos, ela ainda projeta as culturas de um determinado povo e as transmite para as próximas gerações. Com essa ampla função, a língua é estabelecida como “... um autêntico alicerce da estrutura social: além da sua utilidade mais óbvia como instrumento cotidiano das interações humanas, ela possibilita a construção de conhecimentos e sua armazenagem..." (AZEREDO, 2009, pg. 11).

Essa relação entre a língua e os aspectos sociais pode ser identificada nas diferentes fases do desenvolvimento do ser humano. Para aprender sua língua materna, um bebê precisa interagir com um adulto. Dentro da escola, ao relacionar-se com 
seus colegas e professores, as crianças aprendem sobre o respeito, moralidade, diversidade e regras de convivência através de conversas e atividades escritas. Já na fase adulta, o conhecimento é transmitido através de trocas significativas entre sujeitos dentro de diferentes contextos, como ambientes de trabalho e estudo.

Isso ainda pode ser aplicado ao estudo de uma língua estrangeira. Através desse processo, um sujeito poderá obter diversos benefícios, como um maior conhecimento do processo de aquisição linguística no geral, conhecimento cultural diversificado e desenvolvimento de uma visão mais ampla sobre o mundo.

No entanto, devido aos seus formatos únicos, algumas instituições de ensino, sejam universidades, escolas regulares e/ou escolas de idiomas, tendem a priorizar a padronização do ensino de maneira geral. Por exemplo, muitos centros de idiomas, ao tentarem vender seus cursos, afirmam que o aluno irá dominar um idioma dentro de um determinado período de tempo. Logo, a instituição de ensino e o aluno, baseando-se em tal promessa, focam na obtenção do produto, ou seja, o domínio de uma língua estrangeira e, consequentemente, desvalorizam a importância do processo de ensino-aprendizagem. O mesmo ocorre em escolas regulares, mas o objetivo costuma ser centrado na obtenção de boas notas.

Devido à propagação de tal cultura dentro de tais instituições, ou por acreditarem ser a melhor prática, muitos educadores planejam suas aulas baseando-se apenas nos aspectos linguísticos e culturais a serem estudados, como gramática e vocabulário. Ao priorizar apenas conteúdos cognitivos, eles subestimam os aspectos pedagógicos de suas aulas e as necessidades e singularidades de cada aluno, o que pode comprometer a construção efetiva de conhecimento.

A partir desse contexto, o objetivo desta pesquisa é realizar uma reflexão sobre como promover processo mais significativo de ensino e aprendizagem da língua inglesa.Esse trabalho também visa, através da apresentação de diferentes abordagens de ensino, instigar professores de língua inglesa a repensarem sobre suas práticas pedagógicas com o intuito de ajudar seus alunos a construírem conhecimento de maneira mais significativa. 
Para promover tal reflexão, os seguintes questionamentos foram levantados: é possível para um professor preparar e ministrar aulas de Inglês para crianças e adolescentes aplicando apenas seus conhecimentos teóricos sobre língua e cultura? Se sim, o aluno conseguirá aprender de forma efetiva?

Acredita-se que seja possível ensinar Inglês focando apenas nos aspectos linguísticos e culturais expostos pelo professor dentro de sala de aula. No entanto, há a hipótese de que o aluno não conseguirá aprender de maneira tão eficaz, pois ao basear-se apenas em sua disciplina, o educador estará padronizando o conhecimento e negligenciando a individualidade e as necessidades de cada um de seus alunos.

\section{FUNDAMENTAÇÃO TEÓRICA}

\section{O PROCESSO DE ENSINO-APRENDIZAGEM DA LÍNGUA INGLESA}

Segundo Marques (2012, p. 36), Lev Semenovitch Vygotsky acreditava que a aprendizagem tratava-se-se de um processo social. Ao interagir com o outro, o aprendiz começa a percorrer um caminho que se inicia como dependência até atingir sua autonomia através da troca de significações relevantes ao seu contexto sociocultural. Isso também pode ser aplicado à aprendizagem do Inglês.

Quando começa a aprender um novo idioma, o aluno ainda está inseguro e não tem autonomia para produzir frases e textos. Logo, ele irá começar a desenvolver suas habilidades linguísticas baseando-se em seu professor e em seus colegas. Quando finalmente conseguir apropriar-se dos conhecimentos necessários, ele estará pronto para "trabalhar" de maneira independente.

Porém, ao estudar uma língua estrangeira, é importante notar que só focar nos aspectos linguísticos em si não é o suficiente. Afinal, dentro de uma sociedade, a língua é utilizada como instrumento de comunicação e, quando há uma interação social, sempre existem

... dois sujeitos que se comunicam, e a comunicação supõe um contexto social (onde e quando) e uma situação de 
comunicação (como e por quê). Portanto, para que haja comunicação, não basta haver a língua; é necessário que os sujeitos se comuniquem, num tempo e lugar definidos (FARACO;MOURA;MARUXO, 2010, p. 15)

Segundo Ré (2009), uma comunicação efetiva ocorre quando sujeitos alternam turnos, produzem enunciados e conseguem fazer referências, produzindo elementos comuns entre todos os envolvidos. Isso ocorrerá caso haja uma adequação de perspectivas, a construção de um objeto a ser discutido e o desenvolvimento de uma consciência quanto à finalidade da atividade sendo desenvolvida.

Assim, para haver conhecimento completo sobre a língua, os alunos devem entender como ela é utilizada em situações comunicativas do dia a dia e como melhor aplicá-las em diferentes contextos com precisão. Canale e Swain (1980 apud MARQUES, 2012 , p.47) propuseram um modelo que engloba quatro tipos de competências necessárias para a obtenção do domínio da competência comunicativa:

- A competência gramatical ou linguística: trata-se do conhecimento do código linguístico construído pelo sujeito, como vocabulário e formação de frases;

- A competência sociolinguística: refere-se ao papel do falante no contexto e sua escolha de registro/estilo;

- A competência discursiva: aplicação de coesão e coerência em um determinado texto e/ou situação;

- A competência estratégica: trata-se de um conjunto de ações verbais e não verbais utilizadas com o intuito de compensar defasagens na comunicação, como repetição, paráfrase e mudança de estilo.

Portanto, um sujeito, ao tentar comunicar-se deve, em um primeiro momento, ter conhecimento cognitivo sobre a língua para ter ao seu dispor um repertório linguístico rico em vocabulário e conhecimento gramatical. Além disso, ele deve analisar o contexto no qual se encontra e decidir como irá expressar-se. 
Caso seja uma situação mais formal, por exemplo, ele irá utilizar um vocabulário mais técnico e rebuscado, sempre certificando-se de que o conteúdo de sua mensagem seja pertinente à situação. Por fim, caso haja alguma ruptura comunicativa, o sujeito deve compensar esse(s) problema(s) através de estratégias linguísticas.

Outro aspecto a ser levado em consideração no processo de ensino-aprendizagem da língua inglesa são as habilidades linguísticas. Segundo Marques (2012), o ser humano desenvolve duas formas de performances produtivas, a fala e a escrita, e duas formas de performances receptivas, ouvir e ler. É possível observar que “... a comunicação humana sempre foi integrada, pois as habilidades de ouvir e falar, de ler e escrever, respectivamente, representam os dois lados de uma mesma moeda, uma não existem sem a outra!” (MARQUES, 2012, p. 53).

No contexto da educação, todas as habilidades comunicativas devem ser trabalhadas em sala de aula, pois “...nenhuma delas é mais importante que a outra, e desenvolver as quatro é fundamental para o completo preparo dos alunos, já que não sabemos qual delas lhe será necessária no futuro." (MARQUES, 2012, p. 54).

Considerando todos os aspectos apresentados até aqui, a aprendizagem efetiva de um idioma deve integrar, ao mesmo tempo, a competência comunicativa e as habilidades linguísticas. Além disso, nota-se como a significância e autonomia também possuem grande destaque no ensino da língua inglesa, pois de acordo com Venturi (2009, p. 119),

...fatores como relações de poder, afeto e emoção, expectativas culturais, identidade e autoestima são fundamentais no processo de aquisição em L $2^{1}$, bem como o próprio controle desse processo por parte do aprendiz, que constrói seu conhecimento e seu modo de conseguir esse conhecimento...Há um alinhamento claro entre aspectos linguísticos e comunicativos, não sendo possível portanto, classificar quais desses elementos são os mais importantes. Todos possuem o mesmo grau de relevância e, portanto,

Segunda língua. 
cabe ao professor estar ciente de quais abordagens adotar, integrar os aspectos positivos e necessários de cada elemento e aplicá-los às suas aulas para que possa beneficiar o desenvolvimento de cada um de seus alunos.

\section{METODOLOGIA}

Trata-se, neste trabalho, de uma pesquisa bibliográfica. Esse tipo de pesquisa

... procura explicar um problema a partir de referências teóricas publicadas em artigos, livros, dissertações e teses. Pode ser realizada independentemente ou como parte da pesquisa descritiva ou experimental. Em ambos os casos, busca-se conhecer e analisar as contribuições culturais ou científicas do passado sobre determinado assunto, tema ou problema (CERVO; BERVIAN; DA SILVA, 2007, p. 60).

Além disso, há ainda características de uma pesquisa de caráter descritivo. Afinal, segundo Cervo; Bervian; Da Silva (2007), uma pesquisa descritiva observa, analisa e correlaciona fatos e fenômenos sem alterá-los. Ela procura encontrar a frequência com que um fato/fenômeno acontece, sua relação e conexão com outros, sua origem e suas peculiaridades.

A principal meta desse artigo é causar uma reflexão sobre como professores podem promover um processo mais significativo de ensino-aprendizagem da língua inglesa. Dois questionamentos foram levantados com o intuito de nortear essa pesquisa: é possível para um professor preparar e ministrar aulas de Inglês para crianças e adolescentes contando apenas com seus conhecimentos teóricos sobre língua e cultura? Se sim, o aluno conseguirá aprender de maneira eficaz?

Para tentar responder tais perguntas, houve, em um primeiro momento, um levantamento bibliográfico de alguns livros, artigos científicos e teses para fundamentar o processo de ensino-aprendizagem da língua inglesa.

Já para a discussão, foram selecionadas três abordagens de ensino definidas por Marques (2012) e, para cada uma delas, 
foi apresentada uma breve exposição de seus princípios. Além disso, foi desenvolvida uma sequência didática envolvendo todas as metodologias, para ilustrar como um professor pode aplicar tais abordagens dentro de sala de aula a fim de promover uma aprendizagem mais eficaz.

\section{DISCUSSÃO DOS RESULTADOS}

Como abordado na seção da fundamentação teórica, para que o ensino de língua inglesa ocorra com sucesso, o professor deve aplicar as competências comunicativas e as habilidades linguísticas em suas aulas de maneira integrada. Dessa forma, as atividades propostas tornam-se mais dinâmicas, motivadoras e significativas, aumentando assim os níveis de interesse do aluno em relação à matéria.

Marques (2012) apresenta algumas abordagens de ensino que levam todos esses elementos em consideração dentro do processo de ensino-aprendizagem da língua inglesa. Dentre elas pode-se destacar três: a abordagem holística de língua, a aprendizagem através da realização de projetos e o aprendizado por experiência aplicado ao aprendizado de idiomas.

Essas três abordagens foram escolhidas por apresentarem aspectos interessantes - que todos professores deveriam (re) pensar ao planejar suas aulas - como a preparação de cada exercício desafiando diferentes competências do aluno e a importância dos feedbacks dentro de sala de aula. Além disso, “

em todas essas abordagens o foco maior está no conteúdo e no processo, e não no estudo da forma; está em ensinar a língua por meio da comunicação imediata e não em aprender sobre a língua para se comunicar" (MARQUES, 2012, p. 54).

\section{1 A ABORDAGEM HOLÍSTICA DE LÍNGUA}

Segundo Marques (2012), a abordagem holística de língua propaga o conceito de que o aluno deve construir conexões significativas entre o que acontece em seu dia a dia e o que 
acontece em sala de aula. Essas interconexões entre teoria e prática são incentivadas com o intuito de gerar um aprendizado mais profundo e continuo.

Nessa abordagem centrada no aprendiz, a língua é estudada como um todo e não através de divisões independentes. Ligações entre a linguagem oral e escrita são incentivadas para definir objetivos claros e engajar os alunos no processo. Além disso, as ideias de Vygotsky sobre a natureza social da linguagem possuem forte influência nesse tipo de aprendizagem, pois "como um processo social, assume-se que o aprendizado se desenvolve melhor com a colaboração (e a cooperação) entre professor e alunos e entre alunos" (LARSEN-FREEMAN, 2000, apud MARQUES, 2012, p.47).

Todos esses elementos promovem inúmeras possibilidades de atividades a serem aplicadas em sala de aula. No entanto, é importante notar que o professor não deve realizar atividades separadas. Seguindo a ideologia desse tipo de metodologia, ele deve desenvolver seu senso criativo e encontrar maneiras de integrar os tipos de linguagem em todas as atividades, das mais simples às mais complexas.

Por exemplo, se o livro didático apresenta um texto sobre um determinado assunto, o professor pode iniciar a atividade com uma discussão. Fazer perguntas sobre a opinião dos alunos e tentar trazer o tema para sua realidade. Ao realizar tal atividade, antes da leitura, o educador estará aumentando o interesse do grupo sobre o assunto ao levantar questionamentos relacionados ao contexto pessoal de cada um, promovendo, assim, uma oportunidade de prática oral e, também, já os familiarizando com o tema e novo vocabulário.

$\mathrm{Na}$ sequência, o educador deve pedir para os alunos realizarem a própria leitura. Durante ou após esse processo, ele pode tocar o áudio do texto e/ou pedir para os alunos realizarem uma leitura em voz alta para que haja prática das habilidades auditivas e aperfeiçoamento de pronúncia. Exercícios de compreensão também devem ser aplicados para testar interpretação de texto e aguçar as habilidades de leitura.

Por fim, focando na promoção da prática da escrita, o professor ainda pode exigir uma redação relacionada ao tema 
do texto trabalhado. Um texto argumentativo, um email para um amigo, uma história... A proposta deve ser feita levando em consideração o nível do grupo e quais tópicos gramaticais estão sendo estudados. Com esse tipo de atividade, os alunos poderão expor suas opiniões enquanto praticam, havendo, assim, um alinhamento das atividades às necessidades linguísticas dos alunos e aos seus interesses.

\subsection{A APRENdizagem atraVÉs da REALIZAÇÃo DE PRoJetos}

A aprendizagem através da realização de projetos pode ser utilizada para suprir necessidades do grupo através da colaboração de todos. Como os próprios alunos devem escolher o tema, eles tomam um papel mais ativo durante as aulas enquanto exploram seus interesses e/ou necessidades pessoais. Além disso, projetos podem trazer diversos benefícios aos alunos, como aumento de confiança, desenvolvimento de habilidades complexas e formação de senso humanista.

Nesse tipo de aprendizagem

... a necessidade do idioma advém da natureza do projeto e do assunto escolhido pelo grupo. Essa ligação com o mundo fora de sala de aula apresenta aos alunos uma necessidade verdadeira de usarem a língua e não só o de estudar a língua... (Marques, p. 60, 2012).

Larsen-Freeman (2000 apud MARQUES, 2012, p.60) afirma que os projetos são geralmente desenvolvidos em três etapas diferentes: em um primeiro momento, os alunos trabalham dentro da sala de aula, em conjunto com seu professor, elaborando o conteúdo do projeto e prevendo necessidades; em seguida, há a coleta de material, etapa na qual os alunos utilizam as competências de ouvir, falar, ler e escrever de maneira integrada; por fim, os alunos apresentam e reveem o projeto, monitorando todo processo realizado até então e recebendo feedback do professor.

Existem diversas maneiras de se utilizar projetos dentro de sala de aula. No entanto, é importante lembrar que a sua realização deve ser feita baseando-se em um problema, necessi- 
dade ou interesse do grupo. Se, por exemplo, os alunos estejam presenciando uma situação de bullying e gostariam de explorar tal tema, por que não fazê-lo? Qualquer tipo de tópico pode ser válido, pois, por tratar-se de uma aula de inglês, um tema diferente promoverá exposição a novos tipos de materiais, os quais ajudarão a desenvolver vocabulário, gramática e conhecimento de mundo.

Seguindo as etapas descritas anteriormente, os alunos devem começar realizando discussões para decidir como irão tratar do assunto e como o projeto poderá ser feito. Utilizando o exemplo sobre bullying, os alunos podem desenvolver uma campanha anti-bullying dentro da escola, confeccionar cartazes de conscientização ou ainda criar uma peça de teatro em inglês.

Após os objetivos e papeis terem sidos estabelecidos, a execução do projeto inicia-se através de pesquisas. Nessa etapa, os alunos serão expostos a novos vocabulários e estruturas gramaticais através de textos, artigos, vídeos e/ou filmes. Ou seja, eles presenciarão a língua sendo utilizada na prática dentro de situações contextualizadas.

Já na terceira e última etapa, os alunos apresentarão seus resultados e receberão feedback do professor. Essa parte do projeto é de extrema importância, pois nela, o professor poderá dar dicas de como melhorar o projeto e como refinar as habilidades linguísticas. Logo, o grupo aprende com os erros cometidos.

Portanto, com o desenvolvimento de um projeto, é possível integrar todas as habilidades comunicativas da língua enquanto interesses e necessidades do grupo são abordados através da participação de todos.

\subsection{O APRENDIZADO POR EXPERIÊNCIA APLICADO AO APRENDIZADO DE IDIOMAS}

Segundo Marques (2012), a abordagem em questão fornece aos aprendizes experiências concretas através das quais eles constroem hipóteses, conceitos e princípios linguísticos por tentativa e erro. Com técnicas centradas nos alunos, a aprendizagem é promovida através de descobertas de estratégias ativas que os capacitam a tomar controle da própria aprendizagem. 
Assim, pode-se notar que os erros não são reprimidos, mas sim incentivados pois, como explicitado por Menti (2003, p. 20),

O erro é conseqüência [sic!] da aprendizagem e não uma barreira à aprendizagem. Ao mesmo tempo que é um produto natural da aprendizagem, acredita-se que o tratamento de erros seja benéfico à aprendizagem, pois ao receber tratamento de seus erros o aprendiz poderá confirmar e/ou repensar suas hipóteses sobre o funcionamento da $\mathrm{LE}^{2}$ e reformular seus enunciados para ser melhor compreendido enquanto engajado em interação com seus colegas e professores.

Feedbacks corretivos são ferramentas de ensino bastante efetivas no processo de ensino da língua inglesa. Eles dão oportunidade para o professor trabalhar com os erros cometidos pelos alunos de maneira positiva. Menti (2003) menciona seis tipos de feedback corretivos em seu estudo:

- Correção explícita: o professor oferece a forma correta do enunciado e indica que a produção estava incorreta;

- Recast: ao cometer um erro, o professor repete todo ou parte do enunciado do aluno com intuito de fazê-lo compreender quais aspectos foram produzidos de maneira errônea;

- Pedidos de esclarecimento: o professor expressa que não compreendeu o enunciado do aluno e pede por explicações;

- Feedback metalinguístico: movimento corretivo no qual o educador compartilha informações ou perguntas relacionadas à formação correta do enunciado do aluno, promovendo a oportunidade de reflexão sobre os as estruturas linguísticas utilizadas;

- Elicitação: o professor demanda a reformulação do enunciado de maneira direta. Ele começa a corrigir a frase e da oportunidade para o aluno terminar a correção;

Língua escrita 
- Repetição corretiva: o professor repete o enunciado mal formulado, porém enfatizando o erro cometido através de entonação.

Ao planejar uma aula, o professor sempre necessita refletir sobre qual feedback será o mais adequado para cada tipo de atividade. Se estiver havendo uma discussão em grupo, por exemplo, seria interessante utilizar o recast ou um pedido de esclarecimento, pois ambos os tipos podem ser aplicados de forma natural dentro de uma conversa. Caso seja uma apresentação de trabalhos, o professor pode aguardar o término das apresentações para utilizar feedbacks mais diretos ou que exijam maiores explicações, como o feedback metalinguístico ou elicitação.

Esses tipos de técnicas corretivas ainda devem ser utilizados de maneiras variadas com o intuito de fazer o aluno refletir sobre seus erros de maneiras diferentes. Caso sejam utilizadas em excesso e/ou em momentos errados, o filtro afetivo do aluno poderá ser prejudicado com sentimentos de frustração e insegurança. Logo, essa abordagem só irá trazer resultados positivos se o professor for capaz de promover um ambiente amigável e confortável de estudos para que os alunos passem a tratar os erros como elementos naturais no processo de ensino-aprendizagem.

Outra maneira de trabalhar o aprendizado por experiência aplicado ao aprendizado de idiomas é através da elaboração de atividades baseadas nos erros dos alunos. Caso alguns erros sejam cometidos com certa frequência pelo grupo, o professor pode utilizá-los em diferentes tipos de exercícios e até mesmo em jogos.

Após coletar uma boa quantidade de enunciados mal formulados, o professor pode expô-los aos alunos e promover uma competição para ver quem é capaz de ser o primeiro a corrigir todos os erros de maneira adequada. Ou, ainda, utilizar o princípio de classe invertida e pedir para alguns alunos irem à lousa e explicarem determinados tópicos para que todos possam rever certos conceitos e compreender onde estão falhando. Ao aplicar atividades como essas, o educador consegue utilizar os erros para promover construção de conhecimento de maneira coletiva, dinâmica e afetiva. 


\subsection{Proposta de sequência didática \\ E OUTRAS CONSIDERAÇÕES}

Observa-se que todas as metodologias expostas possuem um elemento comum: todas colocam o aluno como centro do processo de atividade enquanto tentam suprir as suas necessidades linguísticas, comunicativas e afetivas de maneira natural e contextualizada. Alguns exemplos e comentários foram explicitados. Mas, para que haja uma visualização mais concreta e prática, a seguinte sequência didática de projeto foi desenvolvida:

TEMA DO PROJETO: família.

OBJETIVo: revisar o vocabulário de membros da família e praticar o uso do verbos to have e to be.

CONTEÚDOS A SEREM ABORDADOS: simple present, focando nos verbos to have e to be.

COMPETÊNCIAS: para a realização do projeto, os alunos irão utilizar todo o conteúdo estudado anteriormente e aplicá-los na execução da competência comunicativa e das quatro habilidades linguísticas (ler, escrever, ouvir e falar).

DESCRIC,ÃO DAS ATIVIDADES DESENVOLVIDAS:

A) Para iniciar o projeto, uma discussão em grupo com algumas perguntas sobre família deve ser promovida. Essas perguntas precisam ser relacionadas com as famílias dos alunos e precisam gerar reflexões acerca do tema. Elas ainda deverão ser estruturadas utilizando estruturas gramaticais e vocabulário previamente estudados. O objetivo dessa primeira etapa é apresentar qual tema será trabalhado e aumentar o interesse dos alunos sobre o assunto.

B) Em seguida, o professor e o grupo devem elaborar o conteúdo do projeto. Os alunos devem decidir como irão trabalhar com o tema proposto. Eles podem montar uma árvore genealógica de suas próprias famílias ou realizar pesquisas sobre diferentes tipos de famílias. Essas podem ser reais ou originadas de séries/filmes/livros. É importante que o professor faça alguns combinados nesse momento, como quais conteúdos e estruturas gramaticais devem ser utilizados, divisão de grupos e prazos de entrega.

c) Depois de estabelecido como trabalharão, o grupo deve realizar pesquisas e coletar os materiais necessários, como imagens, vídeos, filmes, livros, artigos e textos de blog. Para tanto, o professor pode ceder uma aula para que os alunos possam ir ao laboratório de informática ou solicitar pesquisas como lição de casa.

d) A próxima etapa consiste na apresentação dos trabalhos. Nesse momento, os grupos irão compartilhar entre si suas produções. Uma participação constante necessita ser incentivada através da promoção de novas discussões. Para a conclusão do projeto, o professor deve ainda avaliar os grupos, propor sugestões e aplicar um feedback relacionado aos aspectos linguísticos a serem aperfeiçoados.

ACC̃O DOCENTE: o professor precisa acompanhar todas as etapas do processo para certificar-se de que os estudantes estejam compreendendo a proposta e produzindo o material de maneira significativa. Cabe a ele também encorajar o desenvolvimento do trabalho, solucionar dúvidas, propor sugestões e aplicar feedbacks constantes. 
INDICADORES DE AVALIAÇ̃̃o: os alunos devem ser avaliados durante todo o processo. Participação e esforço, coesão e coerência, conteúdo, gramática e apresentação são alguns dos aspectos que podem ser avaliados.

FEEDBACK: os feedbacks devem ser oferecidos durante todo o processo de trabalho. Para as pesquisas e produções textuais, o professor pode auxiliar com um direcionamento mais preciso relacionado aos erros. Após as apresentações, ele deve tentar promover momentos de reflexão e construção de aprendizado. Para tanto, métodos como feedback metalinguístico, elicitação e pedidos de esclarecimento podem ser utilizados.

Essa sequência foi desenvolvida pensando em crianças ou adolescentes de nível básico. Com o livro didático abordando o tema família, esse projeto surge com o intuito de ajudá-los a aperfeiçoar todo o vocabulário e estruturas gramaticais estudados, sanar possíveis dúvidas ainda existentes e também construir conexões significativas entre o assunto e o contexto sociocultural do aluno.

Ademais, eles irão atuar de maneira ativa através de pesquisas, produções textuais e apresentações. Ou seja, eles irão aprender de maneira prática como o conteúdo pode ser utilizado em situações reais de comunicação, características da aprendizagem através da realização de projetos.

As etapas do projeto foram feitas através das sugestões sugeridas no capítulo sobre a abordagem holística da língua. Essa metodologia combina teoria e prática, sempre integrando todos os elementos linguísticos com as necessidades e realidade do aluno. Além disso, em cada etapa do processo, observa-se que diferentes habilidades linguísticas são utilizadas. Durante a pesquisa, por exemplo, os alunos irão ler materiais, escrever textos, escutar áudios e vídeos e discutir oralmente o formato do trabalho.

O aprendizado por experiência aplicado ao aprendizado de idiomas também possui grande importância nessa sequência, pois através de feedbacks, o aluno consegue aprender com seus erros e aperfeiçoar-se cada vez mais.

Logo, conclui-se que não existe uma abordagem melhor ou menos eficaz. Cabe ao educador analisar as singularidades e difi- 
culdades de cada um de seus estudantes e, a partir disso, coletar os aspectos que julga ser mais importantes de cada abordagem para personalizar sua aula da melhor maneira possível.

\section{CONSIDERAÇÕES FINAIS}

O objetivo deste artigo foi discorrer a respeito do processo de ensino e aprendizagem da língua inglesa, levando-se em consideração a utilização de novas estratégias de aprendizagem. Tentou-se atingir tal meta através da apresentação de três abordagens de ensino da língua apresentadas por Marques (2012) e, também, através do desenvolvimento de uma sequência didática como exemplo ilustrativo.

Essa pesquisa foi baseada em duas perguntas: é possível para um professor preparar e ministrar aulas de Inglês baseando-se apenas em seus conhecimentos teóricos sobre língua e cultura? Se sim, o aluno conseguirá aprender de forma efetiva?

Primeiramente, por trabalhar com conhecimento, um professor nunca poderá parar de aperfeiçoar-se tanto em sua matéria como em aspectos pedagógicos. É importante, também, que ele busque ampliar suas ideias sobre o desenvolvimento cognitivo de um sujeito, pois, ao compreender a importância das interações sociais e dinâmicas na construção do conhecimento, ele será capaz de aplicar menos aulas expositivas e tomar um papel de auxiliador. Para isso, ele deve exigir uma postura mais ativa do aluno, desafiando-o sempre a tornar-se responsável por seu próprio desenvolvimento.

Por estar lidando com a língua inglesa, o professor não pode desconsiderar a papel dela como meio de comunicação. Ler, escrever, ouvir e falar... todas as habilidades linguísticas devem ser apresentadas de maneira natural e contextualizada, focando em uso e não somente em estruturas gramaticais e memorização de vocabulário. Portanto, o idioma precisa sempre ser ensinado de maneira significativa, possibilitando ao aluno a compreensão na prática de como utilizá-lo em situações de seu dia a dia.

Por fim, mas não menos importante, outro aspecto de grande valia a ser considerado é a afetividade.A afetividade refere-se a energia e valor responsável por mediar conexões emocionais 
feitas pelo aluno com diversos elementos dentro de sala de aula, como por exemplo seu relacionamento com o professor. Porém, esse valor não deve ser limitado apenas a essa relação, mas, sim aplicado em todas as etapas de preparação de uma aula, como delimitação de objetivos de ensino, organização de conteúdo, preparação de atividades e seleção de métodos avaliativos. Cada um desses processos deve ser desenvolvido com cautela, sempre baseados nas necessidades e interesses de cada estudante.

Simplesmente expor o conteúdo em uma aula é, sem dúvida, uma tarefa mais simples. No entanto, para realmente fazer a diferença e formar sujeitos envolvidos em espirais de conhecimento dinâmicas e de valor, o professor deve sair da sua zona de conforto. Planejamento preciso, organização, criatividade e afetividade são elementos fundamentais para, de fato, transformar o processo de ensino-aprendizagem em algo significativo e mais humanista.

\section{REFERÊNCIAS}

AZEREDO, J. C. Escrevendo pela nova ortografia: como usar as regras do novo acordo ortográfico da língua portuguesa. 3. ed. São Paulo: Publifolha, 2009.

CERVO, A. L ; BERVIAN, P. A. ; DA SILVA, R. Metodologia Científica. 6. ed. São Paulo: Pearson Prentice Hall, 2007.

FARACO, Carlos E; MOURA, Francisco M; MARUXO José H. Gramática. 4. ed. São Paulo: Ática, 2010.

MARQUES, F.S. Ensinar e aprender: o processo comunicativo em sala de aula. Curitiba: InterSaberes, 2012.

MENTI, M. M. Efeito de dois tipos de feedback corretivo, recast e elicitação, no desempenho de alunos de inglês como LE.192 páginas. Dissertação (Mestrado em Letras) - Curso de Pós-graduação em Letras, Universidade Federal do Rio Grande do Sul, Porto Alegre, 2003.

RÉ, A.D. A pesquisa em aquisição da Linguagem: teoria e prática. In: RÉ. A. D. (Org.). Aquisição de linguagem: uma abordagem psicolinguística. 2. ed.São Paulo: Contexto, 2009. 
VENTURI, M. A. Aquisição de língua estrangeira numa perspectiva de estudos aplicados. In: RÉ. A. D. (Org.). Aquisição de linguagem: uma abordagem psicolinguística. 2. ed.São Paulo: Contexto, 2009.

\section{SOBRE OS AUTORES}

Guilherme Garcia de Almeida - Graduado em Letras - Inglês pela Universidade Metodista de São Paulo. Pós-graduado em Psicopedagogia EaD pela Universidade Metodista de São Paulo; Professor de Inglês do centro de línguas do Sesi SP. E-mail: agguilherme.garcia@gmail.com

Lucian da Silva Barros -Psicólogo graduado pela Universidade Católica de Santos. Pós-graduado em Ética, valores e cidadania na escola pela USP; Mestrando em Educação; Professor convidado e orientador de TCC do curso de Psicopedagogia EaD da Universidade Metodista de São Paulo; Docente do Senac SP. E-mail: lucian.barros@hotmail.com 